МОНГОЛОВЕДЕНИЕ

(Монгол судлал)

(Mongolian Studies) (Elista)

Vol. 12, Is. 2, pp. 509-520, 2020

DOI: $10.22162 / 2500-1523-2020-3-509-520$
ISSN 2500-1523 (Print)

ISSN 2712-8059 (Online)

Published since 2002

https://mongoloved.kigiran.com/jour

УДК 811.512

DOI: $10.22162 / 2500-1523-2020-3-509-520$

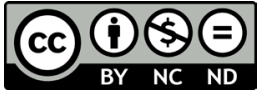

\title{
Особенности ассистивных каузативных конструкций в современном бурятском языке
}

\section{Елена Александровна Дадуева}

\author{
${ }^{1}$ Бурятский институт инфокоммуникаций Сибирского государственного университе- \\ та телекоммуникаций и информатики (д. 152, ул. Трубачеева, 670031 Улан-Удэ, Рос- \\ сийская Федерация) \\ кандидат филологических наук, доцент
}

iD 0000-0002-2562-7331. E-mail: edadueva@yandex.ru

(C) КалмНЦ РАН, 2020

(C) Дадуева Е. А., 2020

Аннотация. Введение. В работе поднимаются проблемы семантики и функционирования ассистива в бурятском языке. Ассистив как одно из частных значений каузативных конструкций находит свое выражение в разных языках мира. Основной целью исследования является рассмотрение отличительных свойств функционирования ассистивности как частного значения каузативности в бурятском языке. Новизна работы заключается в том, что данная проблема в бурятском языке не изучалась. Материалом исследования послужили примеры из разговорной речи и художественных произведений, размещенных в Электронном корпусе бурятского языка (ЭКБЯ). Использованы методы контекстного и дистрибутивного анализа. Результаты. Ассистив в бурятском языке был выделен нами в соответствии с континуальной шкалой семантических типов каузации, в которой существует три значения социативной каузации: совместное действие, ассистив и надзор. В работе отмечается, что ассистив в бурятском языке меняет не только актантную структуру, но и событийно-ролевую структуру каузативной конструкции. Исследование показало, что особенностью ролевой структуры ассистива является то, что место каузатора занимает помощник, а каузатор здесь получает роль дополнения. Рассмотрены особенности конструкций с семантикой ассистива. Выявлено, что ассистивность в исследуемом языке реализуется как в монопредикативных, так и полипредикативных конструкциях. Монопредикативные конструкции предполагают в качестве предикатов глаголы с аффиксом -лса, который представляется нам полифункциональным в бурятском языке и может выражать значение социативной каузации. Полипредикативные конструкции, как показало исследование, выражаются в основном при помощи матричного предиката myhaлха и предикатных актантов в форме причастия будущего времени в дательном или винительном падеже.

Ключевые слова: каузативность, каузативный глагол, социативная каузация, совместное действие, ассистивность, категория залога, прямая каузация, непрямая каузация 
Для цитирования: Дадуева Е. А. Особенности ассистивных каузативных конструкций в современном бурятском языке // Монголоведение. 2020. Т. 12. № 3. С. 509-520. DOI: $10.22162 / 2500-1523-2020-3-509-520$

UDC 811.512

DOI: $10.22162 / 2500-1523-2020-3-509-520$

\title{
Peculiarities of Assistive Causative Constructions in Modern Buryat
}

\section{Elena A. Dadueva ${ }^{1}$}

${ }^{1}$ Buryat Institute of Infocommunications - Ulan-Ude Branch of Siberian State University of Telecommunications and Information Sciences (152, Trubacheev St., Ulan-Ude 670031, Russian Federation)

Cand. Sc. (Philology), Associate Professor

iD 0000-0002-2562-7331. E-mail: edadueva@yandex.ru

\author{
(C) KalmSC RAS, 2020 \\ (C) Dadueva E. A., 2020
}

\begin{abstract}
Introduction. The paper raises the issues of semantics and functioning of the assistive in the Buryat language. The assistive as a special meaning of causative constructions finds its expression in different languages of the world. Goals. The paper aims to consider some distinctive properties inherent to the functioning of assistivity as a particular meaning of causativity in the Buryat language. The novelty of the work is that this problem has not been studied in the Buryat language. Materials and Methods. The study analyzes speech patterns and fiction texts included in the Electronic Corpus of the Buryat Language. The methods of contextual and distributive analysis are used. Results. The assistive in the Buryat language is identified in accordance with the continuum scale of semantic types of causation which implies three meanings of sociative causation: 'joint action', 'assistive', and 'supervision'. The paper notes that the assistive in the Buryat language changes not only the actant structure but also the event-role structure of the causative construction. Our research has shown that a special feature of the role structure of the assistive is that the assistant takes the place of the causer, and the causer here gets the role of a supplement. The work also considers features of constructions with assistive semantics. It is revealed that assistivity in the investigated language is implemented both in mono- and poly-predictive sentence structures. Predicates in mono-predicative constructions are verbs with the affix $-l s a$, which seems poly-functional in the Buryat language and can express the meaning of sociative causation. The research has shown that polyp-predicative constructions are expressed mainly through the matrix predicate tuhalha and the predicate actant in the form of a future participle with indicators of the dative or accusative case.
\end{abstract}

Keywords: causativity, causative verb, sociative causation, joint action, assistive, direct causation, indirect causation, category of voice.

For citation: Dadueva E. A. Peculiarities of Assistive Causative Constructions in Modern Buryat. Mongolian Studies (Elista). 2020. Vol. 12. No. 3. Pp. 509-520. (In Russ.). DOI: 10.22162/2500-1523-2020-3-509-520 


\section{Введение}

В современном языкознании имеется достаточно большое количество работ, посвященных проблемам каузативности. Так, широко освещаются различные традиционные типы каузативов: прямые (контактные) и непрямые (дистантные) каузативы, лексические, морфологические и синтаксические каузативы [Гордон 1981; Недялков 1964; Недялков, Сильницкий 1969; Филиппов 1978; и др.]. Также существует континуальная шкала семантических типов каузации, предложенная М. Шибатани и П. Пардеши вместо традиционных пар каузативов. Согласно их теории, данная шкала содержит и традиционные прямые и непрямые каузативы, между которыми выделяются промежуточные типы, названные социативной каузацией. Такая каузация охватывает переходные виды каузации. К ним относят «совместное действие» (joint action), «ассистив» (assistive) и «надзор» (supervision) [Shibatani, Pardeshi 2002: 90].

В данной статье будет показана только ассистивная разновидность каузативных конструкций бурятского языка. Актуальность работы не вызывает сомнений, так как каузативность много лет представляет собой довольно перспективное направление в изучении грамматики и семантики любого языка, а проблемы ассистивности довольно слабо освещены в лингвистике. В той или иной мере некоторым вопросам ассистивности на материале разных языков уделяется внимание в работах Т. Абдиева, С. А. Оскольской, М. Шибатани, В. П. Недялкова, Л. В. Хохловой и др. [Абдиев 2009; Недялков 1964; Оскольская 2009; Хохлова 2010; Shibatani, Pardeshi 2002].

Новизна исследования определяется тем, что подобные проблемы на материале бурятского языка ранее специально не рассматривались. Основной целью исследования является рассмотрение отличительных свойств функционирования ассистивности как частного значения каузативности в бурятском языке. В задачи исследования входит выделение конструкций, участвующих в выражении значения ассистивности в бурятском языке, выделение их семантических и грамматических особенностей и определение событийно-ролевой структуры.

\section{Материалы и методы}

Материалом исследования послужили примеры из разговорной речи и художественных произведений, размещенных в Электронном корпусе бурятского языка (ЭКБЯ). В тех случаях, если нет указания на ЭКБЯ, примеры были искусственно созданы автором статьи. Использованы методы контекстного и дистрибутивного анализа.

\section{Понятие ассистивности в языке}

Ассистивность как частное значение каузативности - универсальное понятие, применимое для описания любого языка, поэтому естественно, что оно находит свое место и выражение и в бурятском языке, хотя интересен тот факт, что ассистивность отсутствует в некоторых языках, например, в турецком, азербайджанском [Недялков 2004: 20].

Семантика ассистивности заключается в значении помощи в совершении тех или иных действий. Ассистивность - это разновидность социативной каузации, она близка по континуальной шкале каузативов к прямой (контактной) 
каузации, т. е. каузатор непосредственно принимает участие в каузируемом действии. Ассистивные конструкции, как и при прямой каузации, могут иметь признак совмещенности в пространстве и во времени каузирующего и каузируемого события. Например: Би абадаа түлеэ тээлсэнэб 'Я помогаю отцу грузить дрова' - Түлеэн тээлсэгдэжэ байна 'Дрова грузятся'.

С дистантной каузацией ассистивную каузацию объединяет тот факт, что другой участник ситуации, представляющий правый актант, обладает волей. Более того, вероятнее всего, он управляет участником в номинативной функции и контролирует процесс. Но главным отличием представляется то, что действие совершается в большинстве случаев в интересах каузируемого субъекта (бенефициара), в его пользу [Хохлова 2010: 24]. Ср.: Эжы намайе үнеэ hаалгаба 'Мать заставила меня подоить корову' (непрямая опосредованная каузация) - Би эжыдээ үнеэ һаалсанаб 'Я помог матери подоить корову’ (ассистивная каузация). Как мы видим, действие во второй конструкции совершается в интересах каузирумого субъекта (матери). Следует заметить, что важным является то, что в выделении ассистивных конструкций учитывается роль всех участников - каузатора и второго участника. Как и любая каузативная конструкция, ассистивная конструкция имеет двусобытийную структуру: наличие каузирующего и каузируемого события. Каузатор непосредственно принимает участие в каузируемом действии, но не является главным участником, только лишь помогая второму участнику, который и оказывается реальным исполнителем (неноминальным каузатором) воздействия.

Каузатор и помощник выполняют как похожие действия, так и различные. Ср.: Би ябахадань туһалалсааб 'Я помог ему уехать'. Здесь каузатор и его помощник производят разные действия. Эта конструкция может означать, что, скорее всего, помощник оказывал вербальную помощь, помог советом, с покупкой билетов. В таких случаях действия участников разные и не совмещены в пространстве и времени. Например, помог купить билеты сегодня, а уехал второй участник завтра, т. е. результат действий будет виден только в будущем. Если помощь оказывается физически, а не вербально, то действия чаще всего оказываются совмещенными в пространстве и времени. Такие действия можно назвать примерно одинаковыми для обоих участников. Ср.: Би газаа гарахадань эжыдээ туһалааб 'Я помог маме выйти на улицу' (ассистив). Номинатив (Я) здесь выполняет роль помощника, а реальным каузатором, задумавшим и совершающим действие, является дополнение в дативе (эжь-дээ). И каузатор, и бенефициент выполняют похожие физические действия, которые совершаются в одном месте и в одно время. Таким образом, в бурятском языке ассистивность в зависимости от характера помощи может быть близка как к прямой каузации (физическая помощь), так и к непрямой (вербальная помощь).

Каузативная семантика может выражаться как в монопредикативных, так и в полипредикативных конструкциях. Монопредикативные конструкции предполагают, что оба события - и каузирующее, и каузируемое - выражаются при помощи одной лексемы, а полипредикативные конструкции репрезентируют оба события при участии двух лексем. Какие конструкции используются для выражения значения ассистивности в бурятском языке? 


\section{Выражение ассистивности в бурятском языке}

Являясь языковой универсалией, каузативность получает специфическое выражение в разных языках, что, бесспорно, отражает идиоэтническое своеобразие языков. Семантика ассистивности в агглютинативном бурятском языке чаще всего реализуется в монопредикативных конструкциях, т. е. получает морфологическое выражение в одной лексеме. Предикатом в данном случае служит глагол, который имеет аффиксы совместного залога -лса (-лсо,-лсэ). Например: абааша-лса-ха 'помогать нести', һалгаa-лса-ха 'помогать делить' и т. д. Как и во многих агглютинативных языках, набор функций у тех или иных аффиксов может быть различным. Так, суффикс -лса (-лсо,-лсэ) имеет реципрокальную, комитативную и социативную (ассистивную) функции, т. е. мы говорим о его полифункциональности. Суффикс -лда, который наравне с аффиксом -лда используется для обозначения совместного действия, в ассистивных конструкциях не обнаруживается.

Совместный залог, как показывают наши исследования, имеет тесную связь с социативной каузацией [Дадуева, Харанутова 2019]. Данный залог предназначен для обозначения действий, которые совершаются двумя и более участниками. В конструкциях совместного залога один участник выполняет какое-либо действие, а другой только «присоединяется к нему для совместного совершения этого действия» [Санжеев 1963: 57].

Однако, как известно, залоговое значение отличается от каузативного. Наши наблюдения приводят к мысли, что суффикс -лса получает ассистивное значение только в том случае, если он выражает воздействие со строго регламентированной ролевой структурой: каузатор и его помощник (помощники). В этом случае наличие событийно-ролевой структуры в каузативной конструкции существенно отличает ее от залоговой.

Далее важным для нас представляется то, что ассистивы могут быть образованы только от каузативов. Например: $x a a-x a$ 'закрыть что-либо' $\rightarrow x a a-$ лса- $x a$ 'совместно что-либо закрыть или помогать закрыть', тээ-хэ 'грузить' $\rightarrow$ тээ-лсэ-хэ 'помогать грузить' и т.д. Как известно, переходность тесно связана с каузативной семантикой, поэтому такие глаголы образуются от переходных основ [Дадуева 2011; и др.].

Отметим, что присоединение суффикса -лса возможно и к маркированным и немаркированным каузативным глаголам. Например: $x a a-x a$ 'закрыть' (нет каузативного маркирования) $\rightarrow x a a-л c a-x a$ 'помогать закрывать' (ассистивное значение), ор-уул-ха 'ввести' (каузативный показатель -уул) $\rightarrow$ ор-уула-лса-ха ‘ввести вместе с кем-либо’ (ассистивность).

Ассистивное значение глаголов довольно часто отмечается в переводных русско-бурятских словарях. Так, оказывается, что глаголы с аффиксом -лса в словарной статье чаще всего поясняются русским глаголом помогать. Ср: со$x u$-лсо-хо 'помогать кому-либо во время драки', 'помогать кому-либо молотить’, хаха-лса-ха ‘помогать колоть дрова’ и т. д. [Черемисов 1973: 393, 563].

В бурятском языке также возможно выражение ассистивной семантики при помощи полипредикативных конструкций, которые предполагают наличие матричного предиката, выражающего каузативное значение и предикатного актанта. Глагол туhалха 'помогать' в бурятском языке мы выделяем в 
качестве одного из прототипических средств выражения значения ассистивности. Он представляет собой матричный (вершинный) предикат в полипредикативной конструкции. Без сомнения, он выражает категориальное значение ассистивности в чистом виде. Наряду с глаголом туһалха используется форма с аффиксом -лса, обозначающим социативность: туһала-лса-ха 'вместе помогать, участвовать в помощи'. Также у глагола туhалха есть абсолютный синоним хамһа-ха и хамhа-лса-ха 'помогать'.

Предикатный актант при вершинном предикате обычно оформляется в зависимости от типа языка. В русском языке предикатный актант выражается чаще всего инфинитивом, а в агглютинативном бурятском языке в качестве предикатного актанта выступают причастия будущего времени на - $x a$. Причастия как предикатные актанты могут оформляться показателями падежа, в ассистивных конструкциях, как показывает материал, используется датив. Как показывают наблюдения, матричные предикаты, выражающие ассистивное значение, предполагают наличие датива, поэтому канонически данный падеж появляется и в причастии.
1) Эжы-дээ сонх-ые
угаa-ха-да-нь
туһала-лс-ьиш!
Мать-DAT окно-АCC
мыть-PC.FUT-DAT-3 помочь-SOC-IMP
'Помоги матери вымыть окно'.

Как мы видим, показатели притяжания также могут присоединяться к причастному актанту. В данном примере используется показатель 3-го лица -нb, который используется и в ед. и мн. ч. Такое маркирование указывает на лицо и число каузируемого субъекта: 1-е л. ед. ч. -мни, -ни; 1-е л. мн. ч. -мнай, -най; 2-е л. ед. ч. -шни, -ш; 2-е л. мн. ч. -тнай; 3-е л. ед. и мн. ч. -нь. Аффиксы притяжания указывают на помощника. Их основным свойством в бурятском языке является факультативность. Ср.:
2) Эжы-дээ сонхо
yzaа- $x a-\partial a$
Мать-DAT окно-ACC
мыть-PC.FUT-DAT
туһала-лс-ьли!
помочь-SOC-IMP
'Помоги матери вымыть окно'.

Далее отметим, что в качестве предикатных актантов в бурятском языке, кроме причастия, может использоваться деепричастное дополнение. Но оно менее частотно по сравнению с причастными дополнениями. Например:
3) Бадма
Yбhэ-ble
хая-жа
туһала-лса-на
Бадма сено-АСС
бросать-CV
помочь-SOC-PRS.3
'Бадма помогает, бросая сено'.

Также наблюдения показывают, что в каузативных конструкциях с матричным глаголом myhaлxa 'помогать' в бурятском языке в качестве предикатного актанта участвуют существительные в дативе. Чаще всего это существительные, образованные от глаголов, обозначающие опредмеченные действия. Такие отглагольные существительные выражают каузируемые действия, совершаемые в интересах другого лица. Например: 
4)

$\begin{array}{cll}<\ldots>\text { ажал-да, } & \text { һуралсал-да } & \text { туһала-лса-даг } \\ \text { работа-DАТ } & \text { учеба-DАТ } & \text { помочь-SOC-РC. }\end{array}$

‘Помогают работать и учиться’ [ЭКБЯ. Ц. Шагжин. Сэлмэг тэнгэри. 1981].

5) $<\ldots>$ нэгэдэхи

бүлэг-эй

оршуулга-да туһала-лсаа

первая

глава-АСС

перевод-DAТ помочь-SOC 2006].

‘Помог с переводом первой главы’ [ЭКБЯ. Л. Балдан. Монголой уран зохеол.

Стоит отметить, что вместо матричного глагола помогать может использоваться сочетание слов myha хургэхэ 'приносить пользу, помогать'. Напримep:

6) $M Y$

баһа хэлэ

Истинный опять язык-АCC

Үзэ-хэ-дэ

сить-CAUS-CV.3

изучать-PC.FUT-DAT

myha хүр-гэ-дэг

'При этом помогает изучать язык’ [ЭКБЯ. Д. Ц. Жапова. Оньһон үгын синтаксическа түхэл. 2007].

Каузативная конструкция с глаголом myhaлxa (myha хургэхэ) может иметь пятикомпонентную сложную структуру, которая состоит из каузатора, участника-помощника в Им. п., каузирующего действия (вершинный глагол), каузируемого действия (причастие) и каузируемого объекта. Материал исследования показывает, что в данной структуре могут формально отсутствовать те или иные компоненты. Например:

7) Би үналэса-ха-да хамһа-лса-на-б (туһалсанаб).

Я-NOM корова-ACC доить-SOC-PC.FUT-DAT помогать-SOC-PRS-1Sg

'Я помогаю доить корову'.

В этом предложении отсутствует каузатор, т. е. непонятным здесь остается, по чьей инициативе действует участник-помощник, по своей воле или по требованию (просьбе) кого-либо. Здесь либо вообще не было этого компонента - каузатора, либо он просто опущен, но незримо присутствует. Как писал В. С. Храковский, «при ассистивной каузации в отличие от фактитивной и пермиссивной каузаций агенс принимает участие в реализации состояния, каузируемого пациенсу, причем источник импульса каузации остается неизвестным» [Храковский 1973: 126].

\section{Событийно-ролевая структура ассистивной конструкции}

Традиционно каузативные преобразования считаются аргументными, т. е. при образовании каузативной конструкции в структуру предложения добавляется новый агенс. Однако прибавляется не только агенс в аргументной структуре, но и целое событие. Изменение событийной и ролевой структуры в каузативных конструкциях имеет сегодня в лингвистике определяющее значение в их характеристике. Какова событийно-ролевая структура ассистивной конструкции в бурятском языке? Ассистив предполагает присоединение к основному участнику события еще одного участника-помощника. Важным в их 


\section{Монголоведение • Mongolian Studies • $2020 \bullet$ T. 12 • № 3}

ролевой принадлежности является то, что этот участник-помощник оформляется в номинативной функции. Ср.:
8) Доржо
сонхо-ео
шэрдэ-нэ
Доржо-NOM
окно-АСС
красить-PRS.3
‘Доржо красит окно'.
9) Бадма
Доржо-до сонх-ые-нь
Бадма-NOM
Доржо-DAT
окно-АСС-3
шэрдэ-лсэ-нэ
‘Бадма помогает Доржо красить окно'.
красить-SOC-PRS.3

Как мы видим, в предложении (8) Доржо, инициировавший и выполняющий действие, выраженное глаголом шэрдэнэ 'красить', представляет собой каузатора в номинативе и является единственным участником события. Данная конструкция выражает прямую каузацию. В предложении (9) мы видим ассистивную каузацию, здесь вводится еще один участник Бадма, который выступает в роли помощника для Доржо. Однако заметим, что номинатив здесь не является инициатором действия, т. е. он не представляет собой каузатора. Каузатор, который в каузативном событии обычно играет самую главную роль и выражается подлежащим, в этом случае оказывается в нетипичной роли дополнения. Ассистивность вводит в аргументную структуру исходного глагола еще один аргумент, имеющий семантическую роль агенса, который уводит на второй план каузатора и вводит новое событие, включающее действия этого аргумента и каузирование ситуации. Новый участник теперь оформляется в главной номинативной роли. Дериваты с аффиксами -лса (-лсо,-лсэ) обозначают ситуацию, состоящую из двух событий: события, выраженного исходным глаголом, и события с новым агенсом. Введенный участник может «затмить» каузатора исходной ситуации и не просто отвести его на второй план, роль дополнения, но и совсем нейтрализовать участника, инициировавшего действие. В этом случае значение глагола, даже без предыдущего контекста, говорит о том, что присутствует еще один участник, который, вероятнее всего, является организатором каузативного воздействия. Например:

10) Тэрэ басаган тогоо-той мяха гал дээрэһээ гарга-лса-на Ta девушка-NOM котел-COM мясо-ACC огонь-ABL сверху-PSTP вытаскивать-SOC-PRS.3

'Та девушка помогает вытаскивать мясо из котла' [ЭКБЯ. Х. Намсараев. Үүрэй толон. 1959].

В ассистивных конструкциях роли актантов достаточно схожи, но стоит заметить, что участник, обозначенный подлежащим, совершает действия обычно в интересах другого участника каузативной ситуации.

11) Малаадай тогоо-той аарс-ые-нь гарга-лса-на Маладай-NOM котел-COM apca-ACC-3 вытаскивать-SOC-PRS.3

'Маладай помогает вытаскивать арсу из котла' [ЭКБЯ. Х. Намсараев. Эдиршүүд. 1949]. 
Так, новый участник-помощник меняет событийную структуру, уводя каузатора на второстепенную роль, однако даже в этой роли он сохраняет свою агентивную функцию. Мы понимаем, что, несмотря на номинативную роль помощника, каузируемое событие реализуется при вербальном или физическом посредничестве самого каузатора.

Синтаксическое устройство ассистивных конструкций отличается от других типов социативной каузации в бурятском языке. Перераспределение ролей в структуре таких конструкций приводит к тому, что реальный каузатор чаще всего занимает синтаксическую роль дополнения в дативе, т. е. получает роль адресата каузативного воздействия, в чьих интересах и производится каузирумое действие. Дативное маркирование проявляется тогда, когда действие происходит в интересах второго участника, а, как известно, семантика ассистивности предполагает именно значение действия в пользу и интересах бенефициента.

12) Би эюсы-дээ сумк-ьее-нь бари-лса-ба-б

Я-NOM мать-DAT сумка-ACC-3 держать-SOC.CAUS-PST-1Sg

'Я помог матери нести сумку'.

Также нами были выявлено, что в бурятском языке, кроме традиционного оформления в дативе, вполне возможно употребление второго участника в генитиве. Ср.:

13) Би эжы-нгээ сумк-ье-нь бари-лса-ба-б

Я-NOM мать-GEN сумка-ACC-3 держать-SOC.CAUS-PST-1Sg

'Я помог матери нести сумку' (букв. 'Я помогал нести мамину сумку').

\section{4) Елизавета Ефимовна-гай самовар таби-ха-да}

туһала-лса-на

Елизавета Ефимовна-GEN самовар-ACC ставить-ACC-DAT помочь-SOC-PRS.3

'Помогает Елизавете Ефимовне ставить самовар' [ЭКБЯ. Ч. Цыдендамбаев. Түрэл нютагһаa холо. 1958].

Здесь субъект, в интересах которого совершается действие, выражен генитивом. Такие примеры встречаются в ассистивных конструкциях в бурятском языке. Реже такой участник может обозначаться совместным падежом. Чаще всего такие конструкции используются для выражения значения совместного действия («joint action»). Например:
15) Би тэрэ басаган-тэй сонхо
Я та девочка-СОМ окно-ACC закрыть-SOC.CAUS-PST-1Sg
'Я помог той девочке закрыть окно'.

Как можно заметить, в подобных конструкциях мы видим слияние двух значений социативной каузации: здесь есть и сема совместного действия, когда оба участника совершают примерно одинаковые действия, и значение помощи, когда один из участников действует в интересах другого лица. 


\section{Выводы}

Ассистивность представляет собой одно из частных значений каузативности, а именно социативной каузации. Ассистивность в бурятском языке реализуется как в монопредикативных, так и полипредикативных конструкциях. Монопредикативные конструкции предполагают в качестве предикатов глаголы с аффиксом -лса, который представляется нам полифункциональным в бурятском языке, и одной из функций которого является выражение значения социативной каузации. В центре таких конструкций стоят глаголы, традиционно относимые к совместному залогу. Полипредикативные конструкции выражаются в основном при помощи матричного (вершинного) предиката myharxa и предикатных актантов, которые представляют собой причастия будущего времени с показателями дательного или винительного падежа. Также в качестве предикатных актантов в бурятском языке может использоваться деепричастное дополнение, отглагольное существительное, которые выражают каузируемые действия.

Ассистивные конструкции представляют собой полисобытийные ситуации, в которых всегда есть каузирующее событие и каузируемое событие. Такие конструкции обозначают воздействия на каузируемые объекты, вызывающие определенные действия или состояния. Эти воздействия реализуются при участии двух участников, роли которых строго регламентированы ассистивной конструкцией: каузатор и его помощник. Особенностью событийно-ролевой структуры является то, что в ситуацию добавляется участник-помощник, который в бурятском языке становится подлежащим, а каузатор, инициировавший действие, исполняет роль дополнения. Синтаксически такие событийно-ролевые преобразования приводят к тому, что ассистивные конструкции отличаются от остальных видов социативной каузации: реальный каузатор чаще всего в бурятском языке играет синтаксическую роль дополнения в дативе, реже в генитиве и комитативе.

\section{Условные обозначения грамматических значений в глоссах}

ACC - винительный падеж; CAUS — каузативный глагол; COM — совместный падеж; CV — деепричастие; DAT — дательный падеж; FUT - будущее время; GEN - родительный падеж; IMP — повелительное наклонение; INS — инструментальный падеж; NEG — отрицание; NOM — именительный падеж; PC.FUT — причастие будущего времени; Pl - множественное число; SG - единственное число; PRS - настоящее время / PST - прошедшее время; REFL - показатели субъектного (возвратного) притяжания; SOC — социатив; SOC.CAUS - социативный каузатив.

\section{Источники}

ЭКБЯ - Бурятский корпус (электронный корпус бурятского языка) [электронный pecypc] // URL: http://web-corpora.net/BuryatCorpus/search/?interface_language=ru (дата обращения: 02.05.2020).

\section{Sources}

Buryat Corpus (Online Corpus of the Buryat Language). Available at: http://web-corpora. net/BuryatCorpus/search/?interface_language=ru (accessed: May 2, 2020). (In Bur.) 


\section{Языкознание}

\section{Литература}

Абдиев 2009 - Абдиев T. Конструкции с каузативными глаголами в киргизском языке. Бишкек: Киргизско-турецкий университет «Манас», 2009. 114 с.

Гордон 1981 - Гордон Е. Я. Каузативные глаголы в современном русском языке: автореф. дисс. ... канд. филол. наук. М., 1981. 23 с.

Дадуева 2011 - Дадуева E. A. Функционально-семантическая категория каузативности в русском и бурятском языках. Улан-Удэ: Изд-во Бурятского госун-та, 2011. $128 \mathrm{c}$.

Дадуева, Харанутова 2019 - Дадуева Е. А., Харанутова Д. Ш. Социативная каузация в бурятском языке // Oriental Studies. 2019. № 5 (45). С. 966-973.

Недялков 1964 - Недялков В. П. О связи каузативности и пассивности // Ученые записки Башкирского гос. ун-та. XXI. Сер. филол. наук. 1964. № 9. С. 301-310.

Недялков, Сильницкий 1969 - Недялков В. П., Сильницкий Г. Г. Типология морфологического и лексического каузативов // Типология каузативных конструкций. Л.: Наука, 1969. $311 \mathrm{c.}$

Недялков $2004-$ Недялков В. П. Реципрокальные конструкции в тюркских языках (типологическая характеристика) // Международный симпозиум «Синтаксические отношения и структура аргументов» в серии «Языки Европы, Северной и Центральной Азии» (г. Казань, 11-14 мая 2004 г.). Казань, 2004. С. 20-23.

Оскольская 2009 - Оскольская С. А. О глагольных показателях множественности участников в калмыцком языке // Acta Linguistica Petropolitana. Труды института лингвистических исследований. 2009. Т. 5. № 2. С. 310-346.

Санжеев 1963 - Санжеев Г. Д. Сравнительная грамматика монгольских языков. Глагол. М.: Вост. лит., 1963. 266 с.

Филиппов 1978 - Филиппов А. В. К вопросу о каузативных и некаузативных глаголах // Русский язык в школе.1978. № 1. С. 90-93.

Хохлова $2010-$ Хохлова Л. В. Каузативные глаголы в западных новоиндийских языках (хинди-урду, панджаби, гуджарати, раджастхани) // Вестник Московского университета. Серия 13: Востоковедение. 2010. № 3. С. 3-26.

Храковский $1973-$ Храковский В. С. Очерки по общему и арабскому синтаксису. М.: Наука, 1973. 289 с.

Черемисов 1973 - Черемисов К. М. Бурятско-русский словарь. М.: Сов. энциклопедия, $1973.803 \mathrm{c.}$

Shibatani, Pardeshi 2002 - Shibatani M., Pardeshi P. The causative continuum // The Grammar of Causation and Interpersonal Manipulation [Typological Studies in Language]. Vol. 48. Masayoshi Shibatani (ed), Amsterdam: John Benjamins, 2002. Pp. 85-126.

\section{References}

Abdiev T. Kyrgyz Constructions with Causative Verbs. Bishkek: Manas University, 2009. 114 p. (In Russ.)

Cheremisov K. M. Buryat-Russian Dictionary. Moscow: Sovetskaya Entsiklopediya, 1973. 803 p. (In Bur. and Russ.)

Dadueva E. A. Russian and Buryat Languages: Functional-Semantic Category of Causativity. Ulan-Ude: Buryat State University, 2011. 128 p. (In Russ.)

Dadueva E. A., Kharanutova D. Sh. Sociative Causation in the Buryat Language. Oriental Studies. 2019. No. 5 (45). Pp. 966-973. (In Russ.)

Filippov A. V. Causative and non-causative verbs revisited. Russkiy yazyk v shkole. 1978. No. 1. Pp. 90-93. (In Russ.) 
Gordon E. Ya. Causative Verbs in Modern Russian. Cand.Sc. (philology) thesis abstract. Moscow, 1981. 23 p. (In Russ.)

Khokhlova L. V. Causative verbs in new Indo-Aryan languages of Western India. Moscow State University Bulletin. Series 13: Oriental Studies. 2010. No. 3. Pp. 3-26. (In Russ.)

Khrakovsky V. S. Essays on General and Arabic Syntax. Moscow: Nauka, 1973. 289 p. (In Russ.)

Nedyalkov V. P. Reciprocal constructions in Turkic languages: typological characteristics. In: Syntactic Relations and Structure of Arguments. Symposium proc. Ser.: Languages of Europe, North and Central Asia. (Kazan; May 11-14, 2004). Kazan, 2004. Pp. 20-23. (In Russ.)

Nedyalkov V. P. Ties between causativity and passivity revisited. In: Scholarly Notes of Bashkir State University. Vol. XXI. Ser.: Philology. 1964. No. 9. Pp. 301-310. (In Russ.)

Nedyalkov V. P., Silnitsky G. G. Typology of morphological and lexical causatives. In: Typology of Causative Constructions. Morphological Causative. Leningrad: Nauka, 1969. Pp. 20-50. (In Russ.)

Oskolskaya S. A. Kalmyk verbal indicators of plurality. Acta Linguistica Petropolitana. 2009. Vol. 5. No. 2. Pp. 310-346. (In Russ.)

Sanzheev G. D. Comparative Grammar of Mongolic Languages: Verb. Moscow: Vostochnaya Literatura, 1963. 266 p. (In Russ.)

Shibatani M., Pardeshi P. The causative continuum. In: The Grammar of Causation and Interpersonal Manipulation [Typological Studies in Language]. Vol. 48. Masayoshi Shibatani (ed.). Amsterdam: John Benjamins, 2002. Pp. 85-126. (In Eng.) 